Spectrochimica Acta, 2 . No. 12, pp. 1036 to 1050. Pergamon Press Ltd. Printed in Northern Ireland

\title{
The infrared and Raman spectra of the pentafluoroethyl halides
}

\author{
O. RisaIN and R. C. TAYLOR \\ Department of Chemistry, The University of Michigan, Ann Arbor, Michigan
}

(Received 6 August 1959)

\begin{abstract}
The infrared spectra of the pentafluoroethyl halides have been investigated in the gaseous state with double-beam prism spectrometers using $\mathrm{NaCl}$ and $\mathrm{CaF}_{2}$ prisms, and the Raman spectra of the compounds have been obtained for both the gaseous and liquid state. Depolarization ratios were determined for the Raman spectra of the liquids. All eighteen fundamental frequencies have been identified and assigned with the help of the correlation among the spectra of the three compounds. The barrier heights of the potentials hindering internal rotation have been calculated from the observed torsional frequencies assuming rigid groups. An empirical correlation has been observed between the amount of overlap of the fluorine and halogen atoms on the two end groups of the molecule and the contribution of the fluorine-halogen interaction to the barrier height.
\end{abstract}

\section{Introduction}

THE similarities in the vibrational spectra of the pentafluoroethyl halides permit an assignment of the vibrational frequencies to be made with relative ease when the spectra are considered together. In this investigation the infrared and Raman spectra of all three pentafluoroethyl halides have been determined, and all the fundamental frequencies assigned. The assignment differs in some respects from previously published assignments $[1,2,3]$; in particular all eighteen fundamental frequencies have been observed and assigned.

\section{Experimental}

Pentafluoroethyl chloride was made available through the courtesy of Professor J. J. MARTIN of the Chemical Engineering Department of the University of Michigan, who had obtained it from the Jackson laboratories of the E. I. DuPont de Nemours Co. It had been prepared for PVT studies and was further purified by trap to trap distillation. Pentafluoroethyl bromide and iodide were synthesized in this laboratory by the procedure of VoN GROSse et al. [4]. Perfluoropropionic acid, kindly supplied by the Minnesota Mining and Manufacturing Co., was neutralized by $\mathrm{Ag}_{2} \mathrm{O}$, and the silver salt decarboxylated by reaction with the appropriate halogen. The product was purified by passage over $\mathrm{KOH}$ and $\mathrm{P}_{2} \mathrm{O}_{5}$, and was further purified before use by several trap to trap fractionations in a vacuum line. A constant vapor pressure was taken as an indication of purity. The observed spectra show no indication of the presense of sizeable quantities of impurities.

The infrared spectra were recorded by a Perkin-Elmer Model 21 double beam spectrometer equipped with both $\mathrm{CaF}_{2}$ and $\mathrm{NaCl}$ prisms. The Raman spectra

[1] J. R. Nielsen, C. Y. Lrang, R. M. Smith and D. C. SmITH, J. Chem. Phys. 21, 383 (1953).

[2] P. KLABOE and J. R. NrELSEN, J. Chem. Phys. 30, 1375 (1959).

[3] J. R. BARCELo, J. Research Nat. Bur. Standards 44, 521 (1950).

[4] M. Hauptschen and A. Von Grosse, J. Am. Chem. Sac. 73, 2461 (1951). 
were recorded photographically by a Gaertner two prism spectrograph with a linear dispersion of $16 \AA / \mathrm{mm}$. Details of the Raman speotrographic apparatus have been published previously [5]. The Raman spectra of the liquid pentafluoroethyl halides were determined at about $-40^{\circ} \mathrm{C}$, while the spectra of the gases

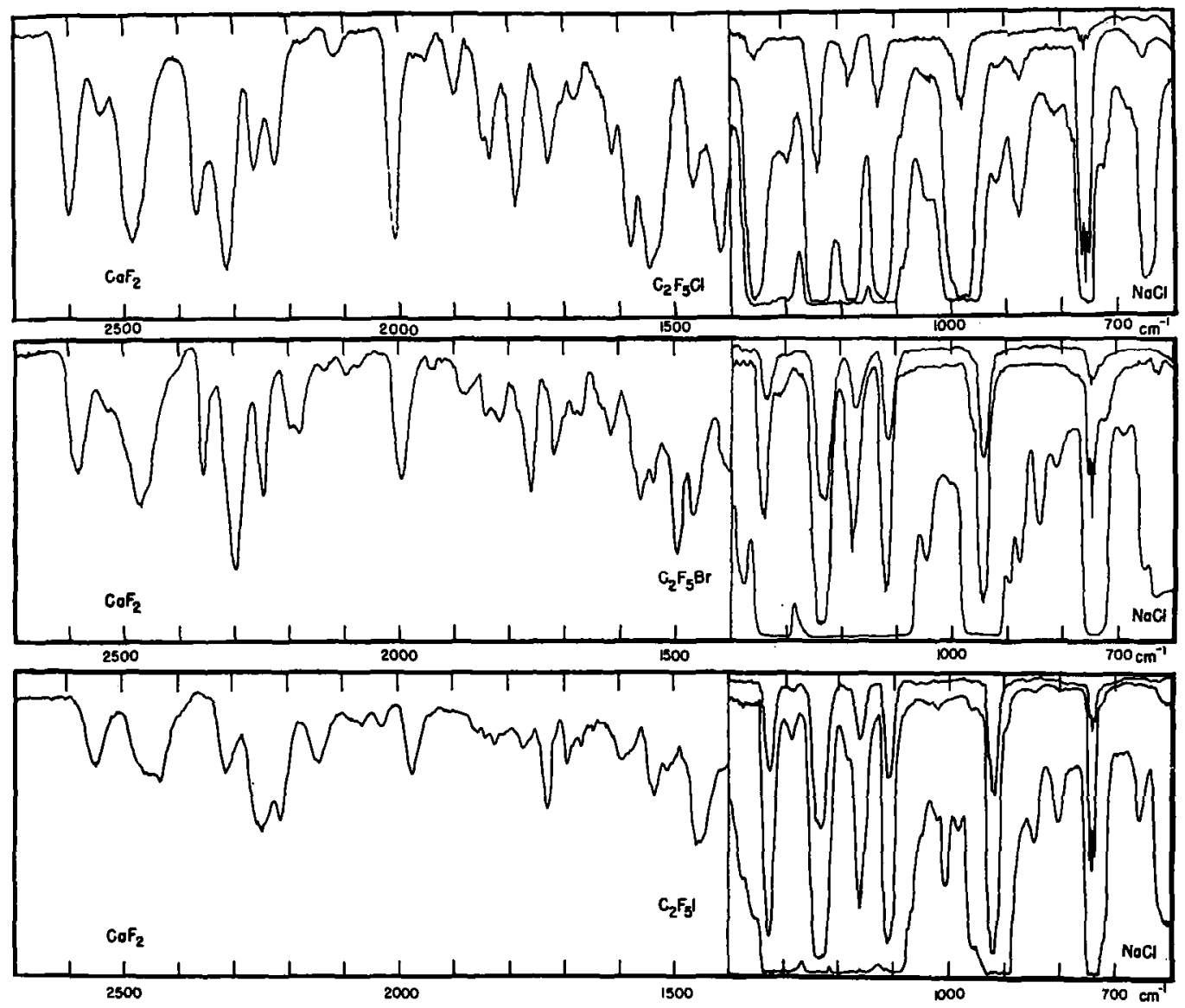

Fig. 1. The infraued spectra of $\mathrm{C}_{2} \mathrm{~F}_{5} \mathrm{Cl}, \mathrm{C}_{2} \mathrm{~F}_{5} \mathrm{Br}$ and $\mathrm{C}_{2} \mathrm{~F}_{5} \mathrm{I}$.

were determined at room temperature and a pressure of about $5 \mathrm{~atm}$. The depolarization ratios of the liquids were determined by the two exposure method using Polaroid cylinders around the sample tubes to polarize the incident light. $\mathrm{C}_{2} \mathrm{~F}_{5} \mathrm{I}$ showed photochemical decomposition even at low temperatures, liberating free iodine, and therefore it was not possible to determine the Raman spectrum of gaseous $\mathrm{C}_{2} \mathrm{~F}_{5} \mathrm{I}$. The infrared spectra of the compounds are reproduced in Fig. 1 and microphotometer records of the Raman spectra are reproduced in Figs. 2 and 3.

\section{Experimental results and assignments}

The pentafluoroethyl halides, if either the eclipsed or the staggered form is the stable configuration, would have just one plane of symmetry and belong to the

[5] R. C. Taylor and G. Vidale, J. Am. Chem. Sac. 78, 294 (1956). 
point group $C_{s}$. One would expect, therefore, eleven $A^{\prime}$ fundamentals polarized in the Raman effect and seven $A^{\prime \prime}$ fundamentals which are depolarized. Because there are many fundamental vibrations of the same symmetry and close frequencies, the possibility of mixing of valence co-ordinates in the normal co-ordinates of vibration is high, and the description of the observed fundamental frequencies in terms of particular valence co-ordinates is probably not very accurate. Nevertheless, the spectra of all'three compounds are quite similar, and by following the

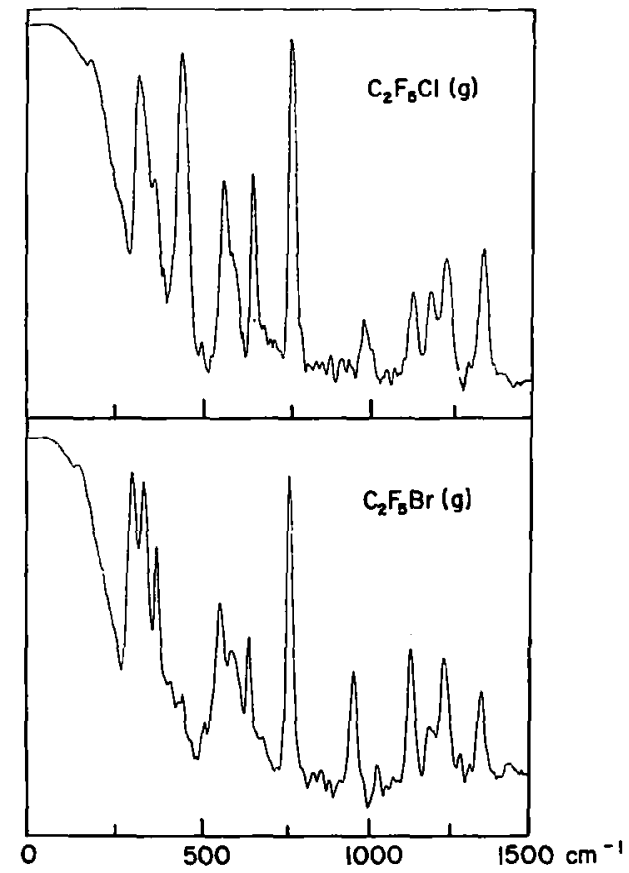

Fig. 2. Microphotometer records of the Raman spectra of gaseous $\mathrm{C}_{2} \mathrm{~F}_{6} \mathrm{Cl}$ and $\mathrm{C}_{2} \mathrm{~F}_{6} \mathrm{Br}$.

increase of intensity of certain groups of frequencies in the Raman effect due to the increase in polarizability in the series $\mathrm{Cl}, \mathrm{Br}$ and $\mathrm{I}$, it is possible to assign certain vibrations to the $\mathrm{CF}_{2} \mathrm{X}$ group. Also, the shift in frequency with increasing halogen mass and the correlation with the spectrum of $\mathrm{C}_{2} \mathrm{~F}_{6}$ are valuable aids in assigning the fundamental modes of the pentafluoroethyl halides.

The highest frequencies necessarily are fluorine stretching modes. The highest frequency in all three halides $\left(1354,1340\right.$ and $1322 \mathrm{~cm}^{-1}$ ) is depolarized in the Raman effect, and shifts relatively little with increasing halogen mass; it is therefore assigned to $\nu_{12}$, an $A$ " stretching mode of the $\mathrm{CF}_{3}$ group derived from one member of $\nu_{7}$, a degenerate vibration of $\mathrm{C}_{2} \mathrm{~F}_{6}$ at $1250 \mathrm{~cm}^{-1}$ with symmetry $E_{4}$. Relative to the other fluorine stretching modes the intensity in the Raman effect decreases with increasing halogen polarizability.

The second highest fluorine stretching mode is complex. The infrared absorption band is broad, with two weak maxima; the center of the band lies at 1240 , 1238 and $1234 \mathrm{~cm}^{-1}$ in the chloride, bromide and iodide, respectively. The Raman spectra of the liquids, however, show a closely spaced pair of lines in the same region 
with the stronger band at 1226,1218 and $1210 \mathrm{~cm}^{-1}$ and the weaker bands at almost the same frequencies as the strong infrared absorption bands. In the Raman spectra of the gas, all the fluorine stretching modes are broad. The $A^{\prime}$ modes do not show the expected sharp $Q$-branch, a result apparently characteristic of fluorocarbons, and therefore the two bands cannot be resolved in the Raman spectrum of the gas. Instead, the observed band oenters $\left(1233\right.$ and $1228 \mathrm{~cm}^{-1}$ in

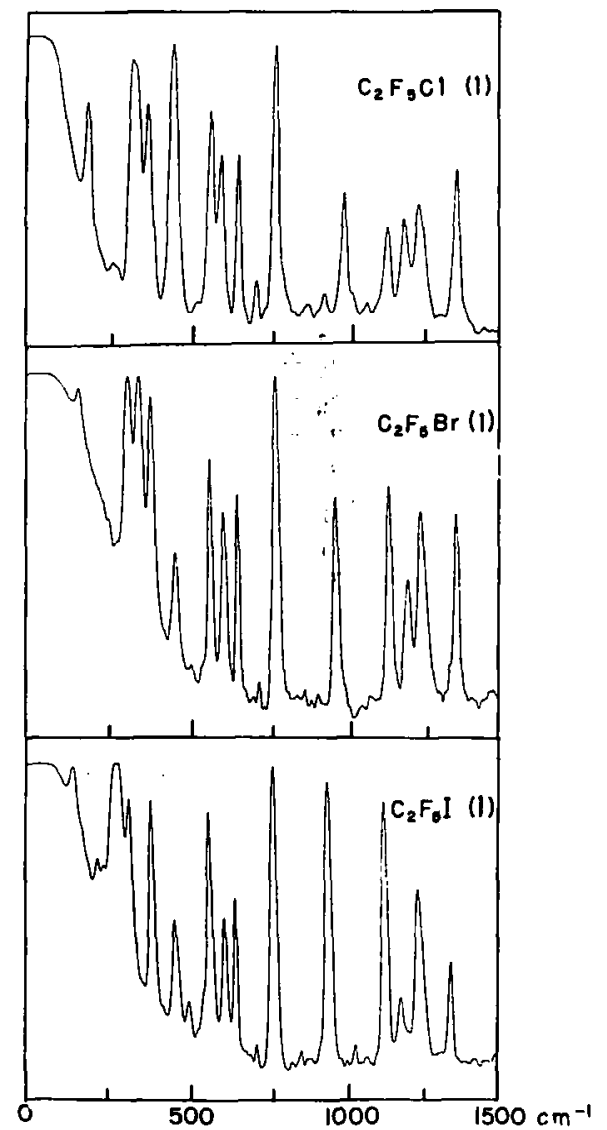

Fig. 3. Microphotometer records of the Raman spectra of liquid $\mathrm{C}_{2} \mathrm{~F}_{6} \mathrm{Cl}, \mathrm{C}_{2} \mathrm{~F}_{5} \mathrm{Br}$ and $\mathrm{C}_{2} \mathrm{~F}_{5} \mathrm{I}$.

the chloride and the bromide) are the averages of the two values of the frequencies in the liquid. It was therefore concluded that there are two closely spaced fundamental frequencies, the higher stronger in the infrared and the lower stronger in the Raman. The conclusion is substantiated by the overtones in the infrared spectrum, where there is a broad band corresponding to the overtone of the strong infrared band, and a weaker shoulder corresponding to a combination between the two frequencies.

Both bands are polarized in the Raman spectra of the liquid, although the measurements are uncertain for the weaker band. They have been assigned to $\nu_{1}$ and $\nu_{2}, A^{\prime}$ fluorine stretching modes of the $\mathrm{CF}_{3}$ group. The higher frequency, $\nu_{1}$, is correlated with the $A_{1 \sigma}$ fluorine stretching mode of $\mathrm{C}_{2} \mathrm{~F}_{6}$ at $1420 \mathrm{~cm}^{-1}$ and 
O. Risons and R. C. TAYLoR

Table 1. Infrared spectrum of $\mathrm{C}_{2} \mathrm{~F}_{5} \mathrm{Cl}$

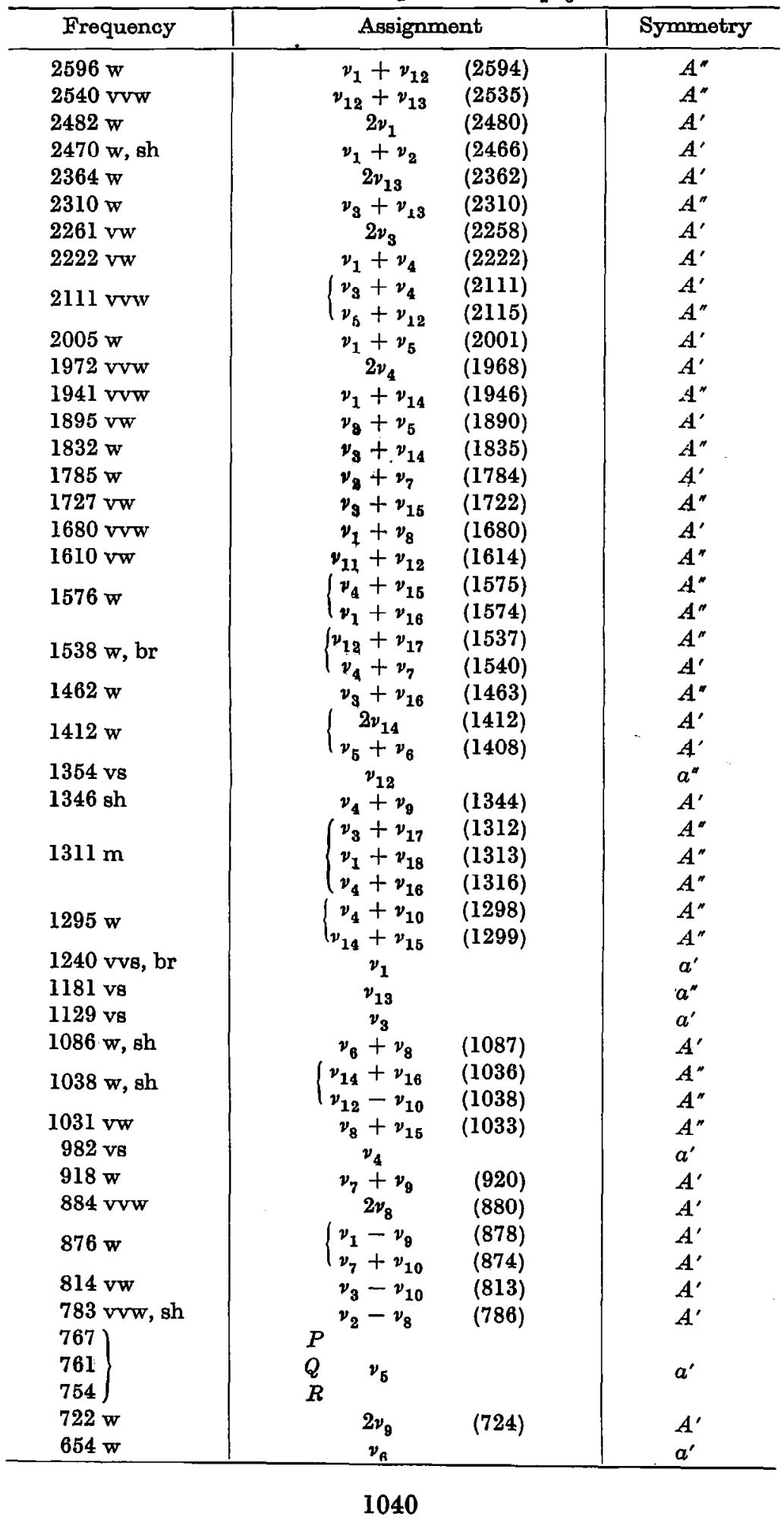


The infrared and Raman spectra of the pentafluoroethyl halides

Table 2. The infrared spectrum of $\mathrm{C}_{2} \mathrm{~F}_{5} \mathrm{Br}$

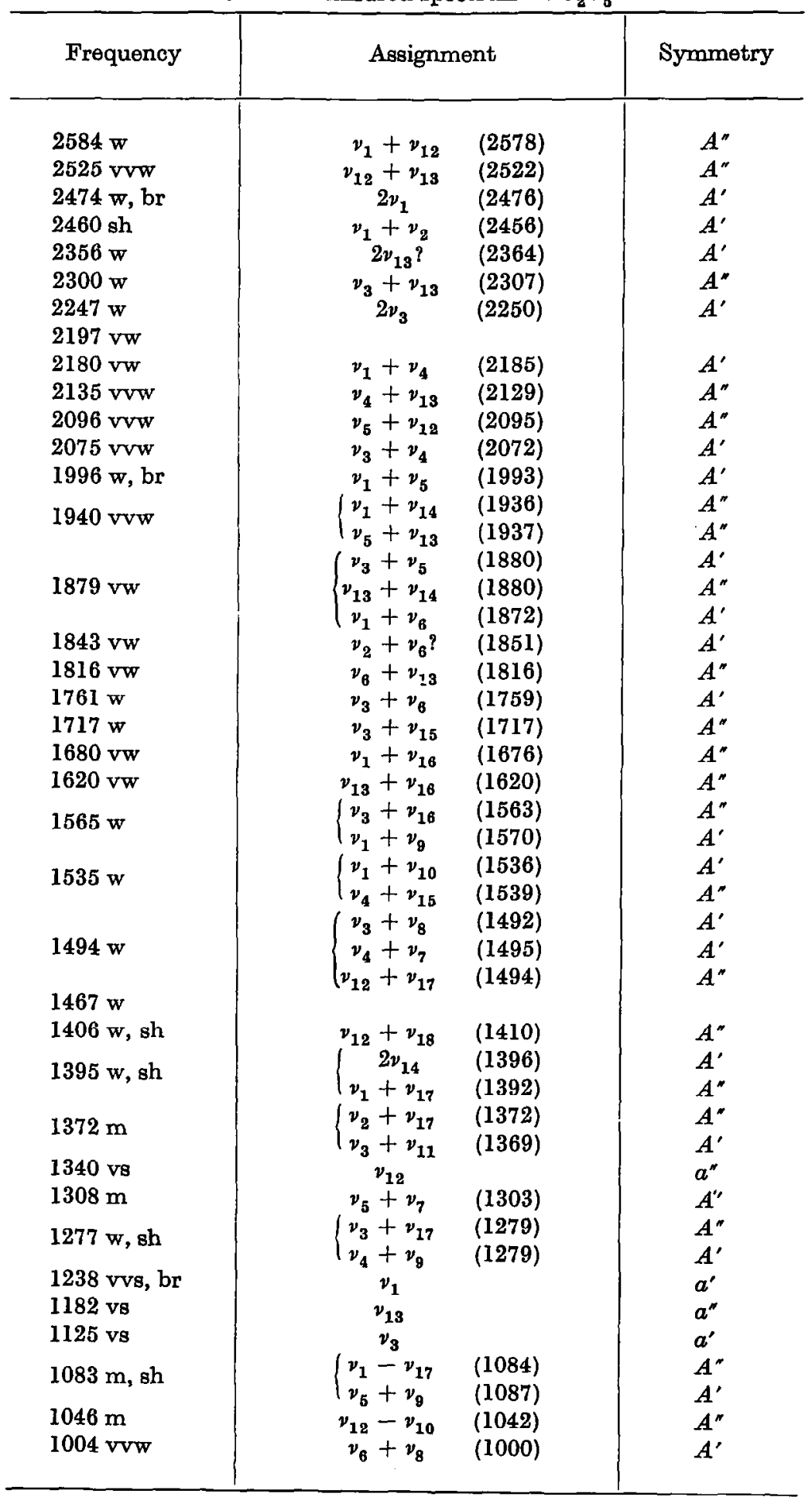




\begin{tabular}{|c|c|c|c|}
\hline Frequency & Assign & & Symmetry \\
\hline 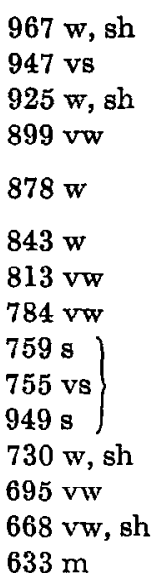 & 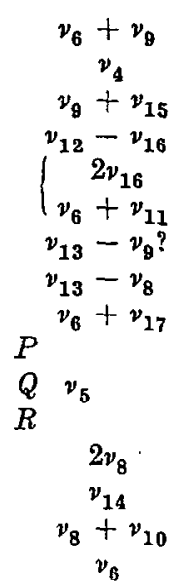 & $\begin{array}{l}(965) \\
\\
(924) \\
(902) \\
(876) \\
(877) \\
(850) \\
(815) \\
(787)\end{array}$ & $\begin{array}{l}A^{\prime} \\
a^{\prime} \\
A^{\prime \prime} \\
A^{\prime \prime} \\
A^{\prime} \\
A^{\prime} \\
A^{\prime \prime} \\
A^{\prime \prime} \\
A^{\prime \prime} \\
a^{\prime} \\
A^{\prime} \\
a^{\prime \prime} \\
A^{\prime} \\
a^{\prime}\end{array}$ \\
\hline
\end{tabular}

the lower frequency, $v_{2}$, is correlated with the other member of the degenerate mode of $\mathrm{C}_{2} \mathrm{~F}_{6}$ at $1250 \mathrm{~cm}^{-1}$. Since both $\nu_{1}$ and $\nu_{2}$ have the same symmetry, the coupling between the two modes must be weak to give such a small splitting. Considering the form of the normal vibrations as similar to the corresponding vibrations in $\mathrm{C}_{2} \mathrm{~F}_{6}, \nu_{1}$ is a simultaneous stretch of all three fluorines, while $\nu_{2}$ is primarily a stretching motion of the fluorine in the symmetry plane of the molecule moving out of phase with the other two. The fundamental $v_{1}$ may possibly be broadened by Fermi resonance with the combination $v_{6}+v_{15}$, which in all three halides falls at about the frequency of $\nu_{1}$; there are other combinations which also could resonate with $\nu_{1}$. The assignment of $\nu_{1}$ and $\nu_{2}$ to the $\mathrm{CF}_{3}$ group is upheld by the low shift of frequency with increasing halogen mass.

The next frequency, 1182,1181 and $1161 \mathrm{~cm}^{-1}$ in the three halides, respectively, is depolarized in the Raman spectrum and has been assigned to $\nu_{13}$, an $A^{\prime \prime}$ stretching mode of the $\mathrm{CF}_{2} \mathrm{X}$ group. It is correlated to one member of the degenerate pair of vibrations of $\mathrm{C}_{2} \mathrm{~F}_{6}$ at $1237 \mathrm{~cm}^{-1}$. The other member of the pair corresponds to the following frequency, 1129,1125 and $1113 \mathrm{~cm}^{-1}$ in $\mathrm{C}_{2} \mathrm{~F}_{5} \mathrm{Cl}, \mathrm{C}_{2} \mathrm{~F}_{5} \mathrm{Br}$ and $\mathrm{C}_{2} \mathrm{~F}_{5} \mathrm{I}$, respectively, which is polarized in the Raman effect. It is assigned to $v_{3}$, an $A^{\prime}$ vibration of the $\mathrm{CF}_{2} \mathrm{X}$ group.

The frequency at 982,947 and $923 \mathrm{~cm}^{-1}$ in the three compounds shows the largest shift in frequency, and also a large increase in intensity in the Raman spectrum on going from $\mathrm{Cl}$ to $\mathrm{I}$. It has been assigned by NIELSEN [1] to the $\mathrm{C}-\mathrm{C}$ stretching mode, but it seems unreasonable that the $\mathrm{C}-\mathrm{C}$ stretching mode should increase in frequency on substitution of a chlorine atom for a fluorine atom. Furthermore, if all the energy of the vibration is concentrated in the motion of the two groups along the carbon-carbon bond, that is, if the molecule is considered as a pseudo-diatomic molecule and the force constant is assumed not to change 
The infrared and Raman spectra of the pentafluoroethyl halides

Table 3. Infrared spectrum of $\mathrm{C}_{2} \mathrm{~F}_{5} \mathrm{I}$

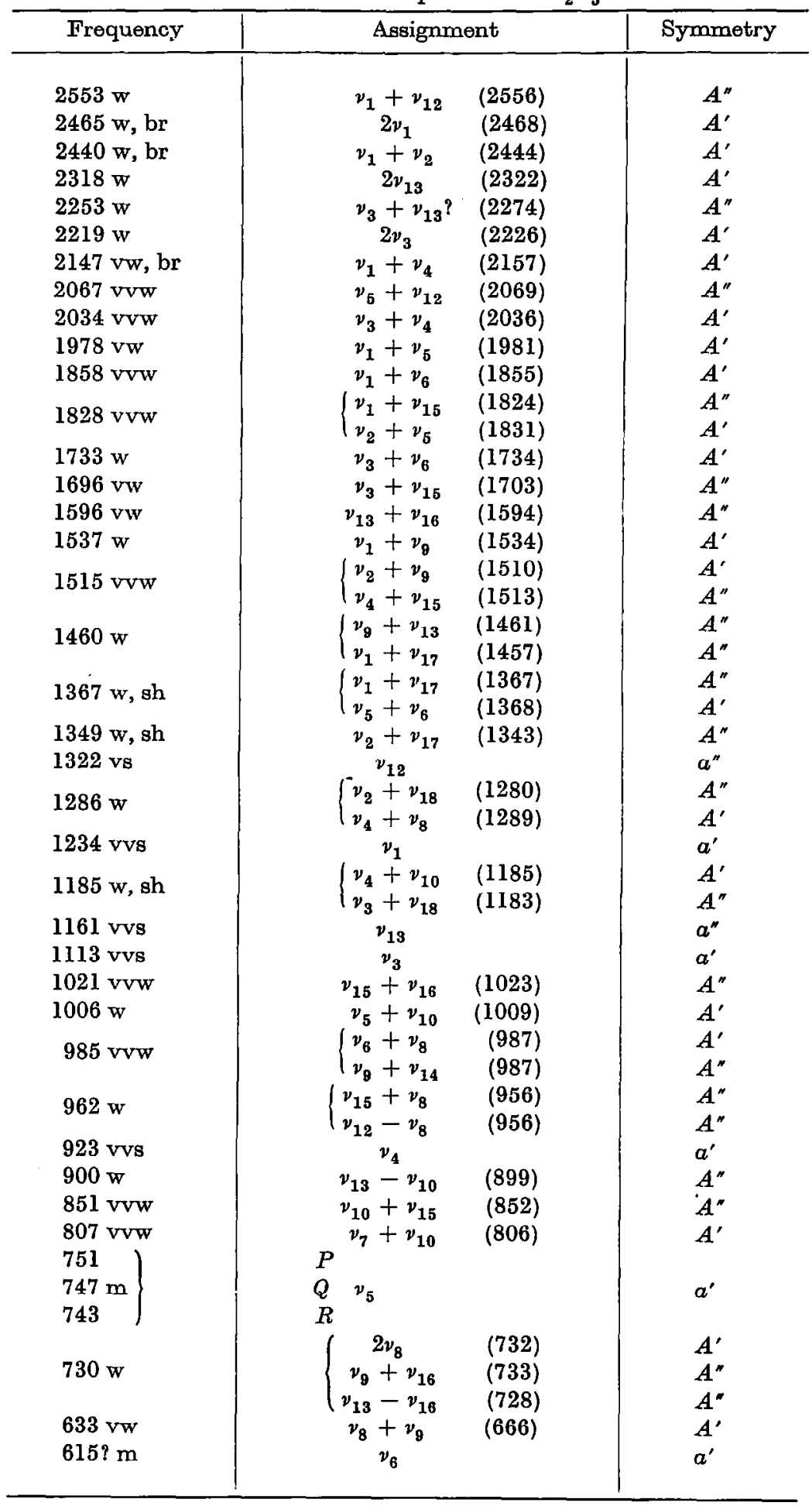


with the change of the halogen substituent, then the calculated shifts in frequency are an upper bound to the observed shifts. If the assumption is correct (and the meager data on the carbon-carbon bond distance in fluorocarbons seem to support it) then the observed shifts are too large to support the assignment of this frequency to the carbon-carbon stretch. The large change in intensity in the Raman effect indicates that this vibration, $v_{4}$, is primarily a halogen stretching motion. However, the value of the frequency is too high to be a pure $\mathrm{C}-\mathrm{X}$ stretch, indicating that there is considerable mixing of co-ordinates in the stretching motions.

The carbon-carbon stretching mode, $v_{5}$, has been assigned to the next frequency at 761,755 and $747 \mathrm{~cm}^{-1}$ for the three halides. This mode is the most intense in the Raman spectrum, and is very highly polarized; it also shows a $P Q R$ structure

Table 4. Raman spectrum of $\mathrm{C}_{2} \mathrm{~F}_{5} \mathrm{Cl}$

\begin{tabular}{|c|c|c|c|}
\hline Liquid & Gas & \multicolumn{2}{|c|}{ Assignment } \\
\hline 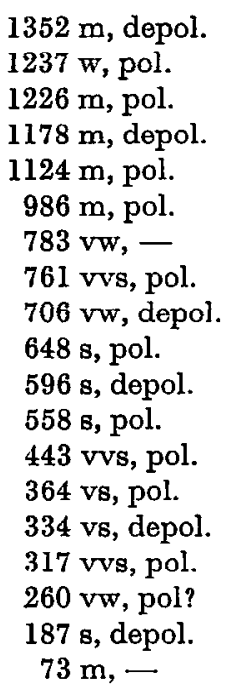 & $\begin{array}{c}1348 \mathrm{w}, \mathrm{br} \\
1233 \mathrm{~m}, \mathrm{br} \\
1181 \mathrm{w}, \mathrm{br} \\
1125 \mathrm{w}, \mathrm{br} \\
978 \mathrm{~m}, \mathrm{br} \\
- \\
760 \mathrm{vs}, \mathrm{sh} \\
- \\
646 \mathrm{~s}, \mathrm{sh} \\
593 \mathrm{~m}, \mathrm{br} \\
558 \mathrm{~m}, \mathrm{sh} \\
440 \mathrm{vs}, \mathrm{sh} \\
362 \mathrm{~s}, \mathrm{sh} \\
334 \mathrm{~m}, \mathrm{br} \\
316 \mathrm{~s}, \mathrm{sh} \\
- \\
183 \mathrm{~m}, \mathrm{br} \\
-\end{array}$ & 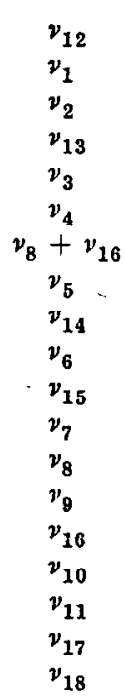 & $\begin{array}{l}a^{\prime \prime} \\
a^{\prime} \\
a^{\prime} \\
a^{\prime \prime} \\
a^{\prime} \\
a^{\prime} \\
A^{\prime \prime} \\
a^{\prime} \\
a^{\prime \prime} \\
a^{\prime} \\
a^{\prime \prime} \\
a^{\prime} \\
a^{\prime} \\
a^{\prime} \\
a^{\prime \prime} \\
a^{\prime} \\
a^{\prime} \\
a^{\prime \prime} \\
a^{\prime \prime}\end{array}$ \\
\hline
\end{tabular}

in the infrared, and is assigned to an $A^{\prime}$ species. Unlike $v_{4}$ it correlates with the C-C stretch in $\mathrm{C}_{2} \mathrm{~F}_{6}$, an $A_{1 g}$ vibration at $809 \mathrm{~cm}^{-1}$. The very high intensity and the very high polarization in the Raman effect support the assignment to the $\mathrm{C}-\mathrm{C}$ stretching mode, as does the moderate shift in frequency with increasing halogen mass. The next frequency is somewhat uncertain. A weak band appears in the Raman spectrum at 706,698 and $687 \mathrm{~cm}^{-1}$, and might possibly be due to the excitation of $\nu_{5}$ by the mercury line at $4347.5 \AA$; however, the band appears in a spectrum excited by the $4046 \AA$ mercury line, and is depolarized, while $\nu_{5}$ is highly polarized. The band appears only very weakly, if at all, in the infrared spectrum. The weak band in the infrared at 722,730 and $730 \mathrm{~cm}^{-1}$ can be explained as a combination enhanced by Fermi resonance with $\nu_{5}$. The Raman bands are therefore 
assigned to an asymmetric fundamental, $v_{14}$, which is correlated to one member of a degenerate $\mathrm{CF}_{3}$ deformation of $\mathrm{C}_{2} \mathrm{~F}_{6}$ at $620 \mathrm{~cm}^{-1}$.

Next comes a group of three closely spaced bands which do not shift much with increasing halogen mass, and which do not increase in intensity with increasing halogen polarizability. The first band, at 646,634 and $621 \mathrm{~cm}^{-1}$ in the three compounds, is definitely polarized and is assigned to $v_{6}$, an $A^{\prime}$ fundamental. Since it can be correlated with the $A_{2 u}$ fundamental at $714 \mathrm{~cm}^{-1}$, it may correspond to the "umbrella" deformation of the $\mathrm{CF}_{3}$ group, but a definite assignment of the fundamentals is this region to particular valence co-ordinates is uncertain at best.

Table 5. Raman spectrum of $\mathrm{C}_{2} \mathrm{~F}_{5} \mathrm{Br}$

\begin{tabular}{|c|c|c|c|}
\hline Liquid & Gas & \multicolumn{2}{|c|}{ Assignment } \\
\hline $\begin{array}{l}1339 \mathrm{~m} \text {, depol. } \\
1312 \mathrm{vvw}- \\
1240 \mathrm{w}, \text { pol? } \\
1218 \mathrm{~m} \text {, pol. } \\
1175 \mathrm{w} \text {, depol. } \\
1114 \mathrm{~m} \text {, pol. } \\
944 \mathrm{~m} \text {, pol. } \\
753 \mathrm{vvs,} \mathrm{pol.} \\
698 \mathrm{vw}- \\
652 \mathrm{vvw}- \\
634 \mathrm{~s} \text {, pol. } \\
592 \mathrm{~s}, \text { depol. } \\
549 \mathrm{~s}, \text { pol. } \\
439 \mathrm{w}, \text { depol. } \\
369 \mathrm{vs,} \mathrm{pol.} \\
332 \mathrm{vs,} \mathrm{pol.} \\
299 \mathrm{vvs,} \mathrm{pol.} \\
245 \mathrm{vw},- \\
222 \mathrm{vw},- \\
153 \mathrm{~s}, \text { depol. } \\
70 \mathrm{~m}, \text { depol? }\end{array}$ & $\begin{array}{c}1340 \mathrm{~m}, \mathrm{br} \\
- \\
1228 \mathrm{~m}, \mathrm{br} \\
1181 \mathrm{w}, \mathrm{br} \\
1123 \mathrm{~m}, \mathrm{br} \\
946 \mathrm{~m}, \mathrm{br} \\
754 \mathrm{vvs}, \mathrm{sh} \\
- \\
- \\
634 \mathrm{~s}, \mathrm{sh} \\
590 \mathrm{~m}, \mathrm{br} \\
548 \mathrm{~s}, \mathrm{sh} \\
438 \mathrm{w}, \mathrm{br} ? \\
367 \mathrm{~s}, \mathrm{sh} \\
332 \mathrm{vs}, \mathrm{sh} \\
298 \mathrm{vs}, \mathrm{sh} \\
- \\
- \\
154 \mathrm{~m}, \mathrm{br} \\
-\end{array}$ & $\begin{array}{l}v_{12} \\
v_{5}+v_{7} \\
v_{1} \\
v_{2} \\
v_{13} \\
v_{3} \\
v_{4} \\
v_{5} \\
v_{14} \\
v_{9}+v_{10} \\
v_{6} \\
v_{15} \\
v_{7} \\
v_{16} \\
v_{8} \\
v_{9} \\
v_{10} \\
v_{10}(\mathrm{H} \\
v_{11} \\
v_{17} \\
v_{18}\end{array}$ & $\begin{array}{l}a^{\prime \prime} \\
A^{\prime} \\
a^{\prime} \\
a^{\prime} \\
a^{\prime \prime} \\
a^{\prime} \\
a^{\prime} \\
a^{\prime} \\
a^{\prime \prime} \\
A^{\prime} \\
a^{\prime} \\
a^{\prime \prime} \\
a^{\prime} \\
a^{\prime \prime} \\
a^{\prime} \\
a^{\prime} \\
a^{\prime} \\
347) \\
a^{\prime} \\
a^{\prime \prime} \\
a^{\prime \prime}\end{array}$ \\
\hline
\end{tabular}

The second band at 593,590 and $590 \mathrm{~cm}^{-1}$ is depolarized and assigned to $v_{15}$, an $A^{\prime \prime}$ deformation of the $\mathrm{CF}_{3}$ group. The third band of the triplet, at 558, 548 and 544 $\mathrm{cm}^{-1}$, is polarized and is assigned to an $A^{\prime}$ fundamental, $\nu_{7}$, of the $\mathrm{CF}_{3}$ group. In the lower frequency region of the pentafluoroethyl halides, the bands in the gas Raman spectra assigned to symmetric motions appear sharp with a definite $Q$ branch while the asymmetric bands are broad. In every case where the bands are intense enough in the gas spectra, the band contour confirms the symmetry assignment based on the depolarization ratios from the liquid spectra; thus the bands in the triplet under discussion are sharp, broad and sharp, respectively.

The band at $440 \mathrm{~cm}^{-1}$ in $\mathrm{C}_{2} \mathrm{~F}_{5} \mathrm{Cl}$ is intense, while the bands at 438 and $433 \mathrm{~cm}^{-1}$ in $\mathrm{C}_{2} \mathrm{~F}_{5} \mathrm{Br}$ and $\mathrm{C}_{2} \mathrm{~F}_{5} \mathrm{I}$ are relatively weak. The band in the chloride is polarized, while the other two are depolarized. The band in $\mathrm{C}_{2} \mathrm{~F}_{5} \mathrm{Cl}$ is therefore assigned to 
the chlorine bending vibration, while the other two are assigned to $\mathrm{CF}_{3}$ bending modes, possibly the asymmetrio rocking mode. The change in the halogen bending mode is the only marked dissimilarity in the spectra of the three pentafluoroethyl halides.

The triplet of low frequency lines in the Raman spectra around $300 \mathrm{~cm}^{-1}$ are the most intense in the spectra. The highest frequency line, at 364, 369 and 366 $\mathrm{cm}^{-1}$ is both polarized and sharp in the Raman spectrum; it is therefore assigned

Table 6. Raman spectrum of $\mathrm{C}_{2} \mathrm{~F}_{5} \mathrm{I}$

\begin{tabular}{|c|c|c|}
\hline Liquid & \multicolumn{2}{|c|}{ Assignment } \\
\hline $1321 \mathrm{w}$, depol. & $\nu_{12}$ & $a^{\prime \prime}$ \\
\hline $1234 \mathrm{w}$, pol? & $\nu_{1}$ & $a^{\prime}$ \\
\hline $1210 \mathrm{~m}$, pol. & $v_{2}$ & $a^{\prime}$ \\
\hline $1153 \mathrm{w}$, depol. & $\nu_{13}$ & $a^{\prime \prime}$ \\
\hline $1100 \mathrm{~m}$, pol. & $\nu_{3}$ & $a^{\prime}$ \\
\hline $917 \mathrm{~s}$, pol. & $v_{4}$ & $a^{\prime}$ \\
\hline 744 vs, pol. & $\nu_{5}$ & $a^{\prime}$ \\
\hline $687 \mathrm{vw},-$ & $\nu_{14}$ & $a^{\prime \prime}$ \\
\hline $622 \mathrm{vs}$, pol. & $v_{6}$ & $a^{\prime}$ \\
\hline $590 \mathrm{~s}$, depol. & $\nu_{15}$ & $a^{\prime \prime}$ \\
\hline $544 \mathrm{vg}$, pol. & $\nu_{7}$ & $a^{\prime}$ \\
\hline $433 \mathrm{~m},-$ & $\nu_{16}$ & $a^{\prime \prime}$ \\
\hline $366 \mathrm{vs}, \mathrm{pol}$ & $\nu_{8}$ & $a^{\prime}$ \\
\hline 300 vs, pol. & $\nu_{9}$ & $a^{\prime}$ \\
\hline 262 vvs, pol. & $\nu_{10}$ & $a^{\prime}$ \\
\hline $223 \mathrm{w},-$ & $v_{11}$ & $a^{\prime}$ \\
\hline $204 \mathrm{w},-$ & $\nu_{10}$ & ( $\mathrm{Hg} \mathrm{4347)}$ \\
\hline $162 \mathrm{vvw},-$ & $v_{10}$ & $(\mathrm{Hg} \mathrm{4339)}$ \\
\hline $133 \mathrm{vs},-$ & $\nu_{17}$ & $a^{\prime \prime}$ \\
\hline $70 ?$ & $v_{18}$ & $a^{\prime \prime}$ \\
\hline
\end{tabular}

to an $A^{\prime}$ fundamental, $v_{9}$ in $\mathrm{C}_{2} \mathrm{~F}_{5} \mathrm{Cl}$ and $v_{8}$ in the other two compounds. The Raman band at $334 \mathrm{~cm}^{-1}$ in the spectrum of $\mathrm{C}_{2} \mathrm{~F}_{5} \mathrm{Cl}$ is both depolarized and broad, and is likely to be an $A^{\prime \prime}$ model, $v_{36}$, an asymmetric bending mode of $\mathrm{CF}_{3}$. However, in $\mathrm{C}_{2} \mathrm{~F}_{5} \mathrm{Cl}$ the mixing of the co-ordinates in the bending modes appears to be more pronounced than in the other two halides. Probably a normal co-ordinate treatment is needed to determine the best description of the fundamentals. The corresponding mode at 332 and $300 \mathrm{~cm}^{-1}$ in the bromide and the iodide is definitely symmetric and corresponds to a symmetric deformation of the $\mathrm{CF}_{2}$ group. The most intense band in the Raman spectrum of $\mathrm{C}_{2} \mathrm{~F}_{5} \mathrm{Br}$ and $\mathrm{C}_{2} \mathrm{~F}_{5} \mathrm{I}$ is the lowest member of the triplet at 298 and $262 \mathrm{~cm}^{-1}$ and can be correlated to the $A_{1 \sigma}$ deformation mode of $\mathrm{C}_{2} \mathrm{~F}_{6}$ at $349 \mathrm{~cm}^{-1}$. Both band contour and depolarization ratio require the band to be $A^{\prime}$; it is assigned because of its intensity to the halogen bending mode. The corresponding frequency in $\mathrm{C}_{2} \mathrm{~F}_{5} \mathrm{Cl}$, at $317 \mathrm{~cm}^{-1}$, is also symmetric, and corresponds to a $\mathrm{CF}_{2}$ deformation. 
There is a weak Raman line at 260,222 and $223 \mathrm{~cm}^{-1}$ whose depolarization ratio could not be determined accurately, but which seemed to be polarized. It is assigned in all three compounds to the symmetric $\mathrm{CF}_{3}$ rocking mode, $\nu_{11}$. The more intense, broad and depolarized Raman band at 187,154 and $133 \mathrm{~cm}^{-1}$ is assigned to the asymmetric $A^{\prime \prime} \mathrm{CF}_{2} \mathrm{X}$ rocking mode. Both of these frequencies can be correlated to a degenerate $E_{u}$ rooking mode of $\mathrm{C}_{2} \mathrm{~F}_{6}$. Finally, the lowest frequency must, by elimination, correspond to the torsional oscillation. In $\mathrm{C}_{2} \mathrm{~F}_{5} \mathrm{Cl}$ and

Table 7. Fundamental frequencies of the pentafluoroethyl halides

\begin{tabular}{|c|c|c|c|c|c|}
\hline & & Chloride & Bromide & Iodide & \\
\hline$a^{\prime}$ & $\begin{array}{l}v_{1} \\
v_{2} \\
v_{3} \\
v_{4} \\
v_{5} \\
v_{6} \\
v_{7} \\
v_{8} \\
v_{9} \\
v_{10} \\
v_{11}\end{array}$ & $\begin{array}{r}1240 \\
1226 \\
1129 \\
982 \\
761 \\
647 \\
558 \\
440 \\
362 \\
316 \\
260\end{array}$ & $\begin{array}{r}1238 \\
1218 \\
1125 \\
947 \\
755 \\
633 \\
548 \\
367 \\
332 \\
298 \\
221\end{array}$ & $\begin{array}{r}1234 \\
1210 \\
1113 \\
923 \\
747 \\
621 \\
544 \\
366 \\
300 \\
262 \\
223\end{array}$ & $\begin{array}{l}\mathrm{CF}_{3} \text { stretch } \\
\mathrm{CF}_{3} \text { stretch } \\
\mathrm{CF}_{2} \text { stretch } \\
\mathrm{CF}_{2} \mathrm{X} \text { stretch } \\
\mathrm{C}-\mathrm{C} \text { stretch } \\
\mathrm{CF}_{3} \text { deformation } \\
\mathrm{CF}_{3} \text { deformation } \\
\mathrm{C}-\mathrm{Cl} \text { bend; } \mathrm{CF}_{2} \text { rock } \\
\mathrm{CF}_{2} \text { deformation } \\
\mathrm{CF}_{2} \text { deform; C-X bend } \\
\mathrm{CF}_{3} \text { rock }\end{array}$ \\
\hline$a^{\prime \prime}$ & $\begin{array}{l}\nu_{12} \\
\nu_{13} \\
\nu_{14} \\
\nu_{15} \\
\nu_{16} \\
\nu_{17} \\
\nu_{18}\end{array}$ & $\begin{array}{r}1354 \\
1181 \\
706 \\
593 \\
334 \\
183 \\
73\end{array}$ & $\begin{array}{r}1340 \\
1182 \\
698 \\
590 \\
438 \\
154 \\
70\end{array}$ & $\begin{array}{r}1321 \\
1161 \\
687 \\
590 \\
433 \\
133 \\
70 ?\end{array}$ & $\begin{array}{l}\mathrm{CF}_{3} \text { stretch } \\
\mathrm{CF}_{2} \text { stretch } \\
\mathrm{CF}_{3} \text { deformation } \\
\mathrm{CF}_{3} \text { deformation } \\
\mathrm{CF}_{3} \text { rock } \\
\mathrm{CF}_{2} \mathrm{X} \text { rock } \\
\text { Torsion }\end{array}$ \\
\hline
\end{tabular}

$\mathrm{C}_{2} \mathrm{~F}_{5} \mathrm{Br}$ the lowest frequency is resolved from the exciting line, and the frequency is well established at 73 and $70 \mathrm{~cm}^{-1}$ in the spectra of the liquids. The torsional oscillation of $\mathrm{C}_{2} \mathrm{~F}_{5} \mathrm{I}$ is more intense, and was not too well resolved from the exciting line; its frequency is estimated at about $70 \mathrm{~cm}^{-1}$.

\section{Discussion}

In general, the infrared spectra of $\mathrm{C}_{2} \mathrm{~F}_{5} \mathrm{Cl}$ and $\mathrm{C}_{2} \mathrm{~F}_{5} \mathrm{Br}$ agree within experimental error with the previously published results of NIELSEN and BARCELO $[1,2,3]$. Additional bands have been found in the Raman spectra of the liquids, and consequently the interpretation of the spectra is somewhat different. NIELSEN assigned the highest fundamental to an $A^{\prime}$ mode, but the depolarization measurements and the infrared band contours both indicate that this band is an $A^{\prime \prime}$ mode in all three halides. He also found two closely spaced bands in the Raman spectrum of $\mathrm{C}_{2} \mathrm{~F}_{5} \mathrm{Cl}$ in the vicinity of $1230 \mathrm{~cm}^{-1}$, but only one band in $\mathrm{C}_{2} \mathrm{~F}_{5} \mathrm{Br}$. In this investigation it was found that two closely spaced bands occurred in this region in 


\section{O. Risgn and R. C. TAYLOR}

all three halides, and that the frequencies of all the other fluorine stretching modes shifted little in the Raman spectra with change of state. Therefore both frequenoies were assigned to fundamental modes. In general it was found that the fluorine stretching modes were little affected by changes of halogen in the molecule.

Another point of disagreement with NIELSEN's assignment $[1,2]$ is the designation of the $\mathrm{C}-\mathrm{X}$ and $\mathrm{C}-\mathrm{C}$ stretching modes. The assignments of NuEsSEN have been reversed for the redsons given earlier; the present assignment is also supported by the appearance of two bands around $900 \mathrm{~cm}^{-1}$ in $\mathrm{CF}_{3} \mathrm{CFCl}_{2}$ [1], in the region to which the $\mathrm{C}-\mathrm{X}$ stretch has been assigned. The frequency of the $\mathrm{C}-\mathrm{X}$ stretch is high, and probably there is some mixing of co-ordinates, of $\mathrm{C}-\mathrm{Cl}$ and $\mathrm{C}-\mathrm{F}$ stretches in $\mathrm{C}_{2} \mathrm{~F}_{5} \mathrm{Cl}$ and of $\mathrm{C}-\mathrm{I}$ and $\mathrm{C}-\mathrm{C}$ stretches in $\mathrm{C}_{2} \mathrm{~F}_{5} \mathrm{I}$.

NIELSEN [1] found that the band in $\mathrm{C}_{2} \mathrm{~F}_{5} \mathrm{Cl}$ at about $440 \mathrm{~cm}^{-1}$ in the Raman spectrum did not coincide with a band in the infrared spectrum at about $454 \mathrm{~cm}^{-1}$, and therefore assigned both bands to fundamentals. However, no evidence was found in the Raman spectrum of either liquid or gas for the presence of two bands in this region, and apparently the two bands correspond to the same vibration. He also stated that the band at about $183 \mathrm{~cm}^{-1}$ was a composite of an $A^{\prime}$ and an $A^{\prime \prime}$ vibration, but it was found that this band is completely depolarized and therefore should belong to an $A^{\prime \prime}$ vibration. Those fundamentals assigned by NrwLSEN to bands not confirmed by the present work have been reassigned.

For $\mathrm{C}_{2} \mathrm{~F}_{5} \mathrm{Br}$, NLelsen [2] reported that the band at $299 \mathrm{~cm}^{-1}$ was a composite band. However, its depolarization ratio was found to be of the same magnitude as that of the other $A^{\prime}$ bending modes, and no shift in frequency was noted between the parallel and perpendicular components of the Raman band; it is therefore assigned to a simple $A^{\prime}$ vibration. Similarly, in this investigtion no evidence of a Raman band was found at $167 \mathrm{~cm}^{-1}$ where NIELSEN had reported a very weak band. None of the Raman bands underwent a shift of frequency with a change of polarization, so it was concluded that none of them were composed of two partially resolved superimposed bands.

The strongest evidence for the correctness of the present assignment is the correlation diagram, which shows a high degree of regularity (Fig. 4). The relative intensities shown are those of the Raman spectra of the liquids, enabling one to follow the increase of intensity due to increasing halogen polarizability in the frequencies associated with the vibrations involving the halogen substituent. For comparison, the fundamental frequencies of $\mathrm{C}_{2} \mathrm{~F}_{6}$ taken from the papers of Nielsen, Richards and McMurray [6] and Rank and Pace [7] are included in the diagram. The correlation diagram is most useful in a series of homologous compounds such as the pentafluoroethyl halides where the chemical bonding changes very little and where the force fields of the molecules would be expected to be quite similar. The fact that such a regular correlation can be made is excellent evidence for the correctness of the assignment.

The torsional oscillation frequency was observed in all three halides, although the value of the frequency is least certain for $\mathrm{C}_{2} \mathrm{~F}_{5} \mathrm{I}$. From the observed frequencies

[6] J. R. NIELSEN, C. M. Riohards and H. L. MoMurry, J. Chem. Phys. 16, 67 (1948).

[7] D. H. RarK and E. L. PACE, J. Chem. Phys. 15, 39 (1947). 
The infrared and Ramen spectra of the pentafluoroethyl halides

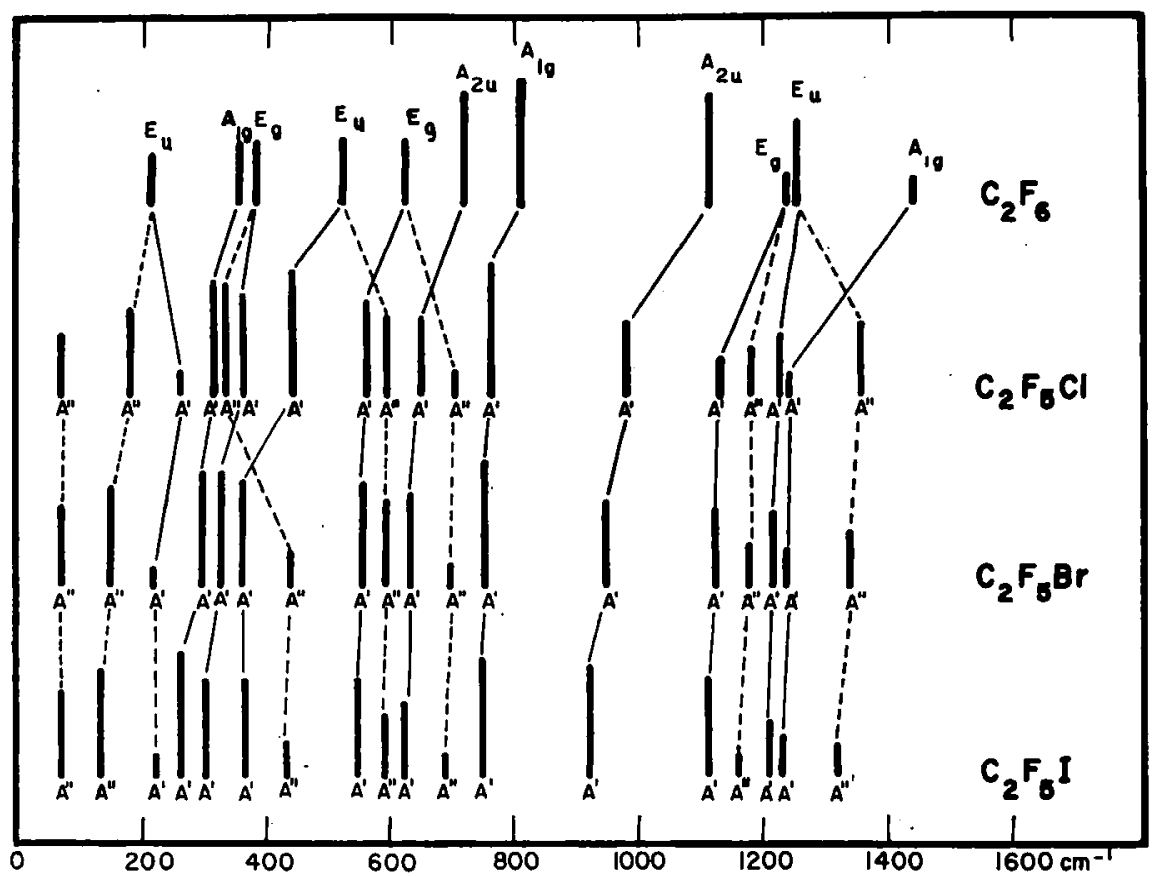

Fig. 4. Correlation diagram for the fundamental frequencies of hexafluoroethene and the pentafluoroethyl halides.

the barrier heights of the potential hindering rotation were calculated under the usual assumptions of a sinusoidal potential function and rigid rotation about the $\mathrm{C}-\mathrm{C}$ axis [8]. Bond distances and angles were taken from the trifluoromethyl halides, whose structural parameters have been measured accurately by electron diffraction using the sector method [9]. The barrier heights so determined are listed in Table 8; they increase in a regular fashion with increasing halogen size suggesting that repulsion between non-bonding orbitals is the main factor in the hindering potential. The barrier height for $\mathrm{C}_{2} \mathrm{~F}_{6}$ as estimated by PACE [10] is included for comparison.

Table 8. Potential barriers restricting internal rotation for the pentafluoroethyl halides

\begin{tabular}{l|l}
\hline Compound & $\begin{array}{c}\text { Barrier } \\
\left(\mathrm{cm}^{-1}\right)\end{array}$ \\
\hline & $1521^{*}$ \\
$\mathrm{C}_{2} \mathrm{~F}_{6}$ & 1984 \\
$\mathrm{C}_{2} \mathrm{~F}_{5} \mathrm{Cl}$ & 2237 \\
$\mathrm{C}_{2} \mathrm{~F}_{5} \mathrm{Br}$ & 2480 \\
$\mathrm{C}_{2} \mathrm{~F}_{5} \mathrm{I}$ & \\
\hline
\end{tabular}

* Ref. [8].

[8] G. HrrzBerg, Infra-red and Raman Spectra p. 226. van Nostrand, New York (1945).

[9] I. S. Bartell and L. O. BrookwaY, J. Chem. Phys. 23, 1860 (1955); R. E. ANDerson, Thesis, University of Michigan (1956).

[10] E. L. PAOE, J. Chem. Phys. 16, 74 (1948). 
An interesting empirical correlation was found between the observed barrier heights and the overlap of the interacting atoms. The distance between a fluorine atom on the $\mathrm{CF}_{3}$ group and the halogen atom on the other end of the molecule was calculated assuming the end groups to be rigid and the molecule in the eclipsed configuration, and taking the $\mathrm{C}-\mathrm{C}$ distance to be $1.52 \AA$. The difference between the sum of the Van der Waal's radii of the two atoms [11] and the calculated interatomic distance was taken to be a qualitative measure of the overlap of the non-bonding orbitals of the two atoms. It was then assumed that the potential barrier hindering rotation could be separated into a sum of three terms representing

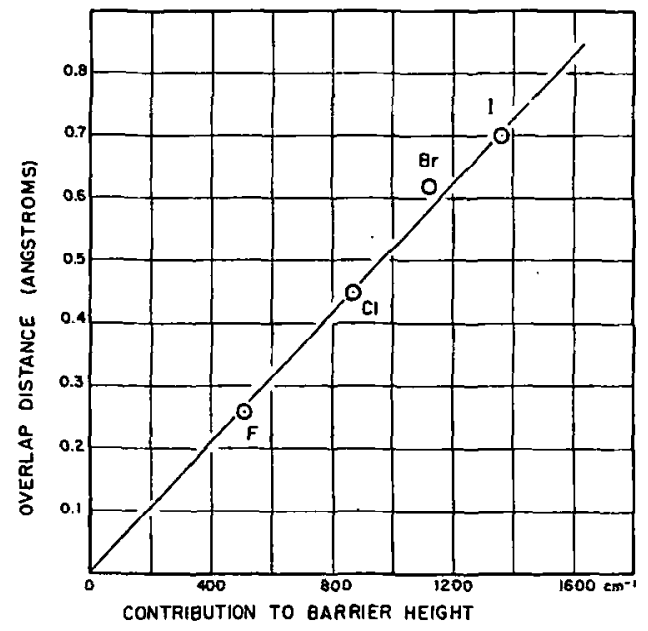

Fig. 5. Empirical correlation between the amount of overlap of opposing fluorine and halogen atoms and the contribution of their interaction to the barrier height of the potential restricting internal rotation.

the pairwise interactions of the three atoms of one end group with the corresponding atoms of the other end group, and that the terms representing the $F-F$ interactions were constant in all four members of the series of compounds. The contribution to the hindering potential from the $F-X$ interaction was then calculated by subtracting two-thirds of the barrier height in $\mathrm{C}_{2} \mathrm{~F}_{6}$, corresponding to the contribution of two $F-F$ interactions. When the amount of overlap was plotted against the contribution to the barrier height from the $F-X$ interaction, the points were found to lie on a straight line passing through the origin (Fig. 5). It would appear, then, that if there were no overlap there would be no hindering potential, a result expected if the potential barrier is due primarily to repulsive interaction of non-bonding orbitals. This conclusion is plausible on physical grounds as well; if the barrier were due to dipole-dipole interaction, it would be expected to decrease in the series of the halogens, since the bond moment of the $\mathrm{C}-\mathrm{X}$ bond decreases on going from $\mathrm{F}$ to $\mathrm{I}$. If the barrier were due to induced dipole moments, then the potential would be attractive, not repulsive, and the barrier height would decrease with the increasing polarizability of the halogen atom.

[11] J. A. A. KetelaAR, Chemical Constitution (2nd Ed.) p. 201. Amsterdam (1958). 